\title{
Scintillation measurements over False Bay, South Africa
}

\author{
M. van Iersel ${ }^{* a}$, A.M.J. van Eijk ${ }^{\mathrm{a}, \mathrm{b}}$ \\ ${ }^{a}$ TNO, Oude Waalsdorperweg 63, 2597 AK, Den Haag, the Netherlands \\ bLaboratoire de Mécanique de Fluides UMR 6598 CNRS, Ecole Centrale de Nantes, B.P. 92101, \\ 44321 Nantes Cedex 3, France
}

\begin{abstract}
A commercial long-range scintillometer was deployed over a 2-km path in False Bay, South Africa, for a timeframe of one year. The turbulence data retrieved from the instrument are compared to turbulence parameters inferred from micrometeorological data and models, and the relation between experimental and model-data is explored.
\end{abstract}

Keywords: Scintillation, atmospheric turbulence, scintillometer

\section{INTRODUCTION}

Electro-optical (EO) signals propagating through the atmosphere can be distorted by intensity fluctuations in the atmosphere. Such a turbulent atmosphere is related to the inhomogeneities in the refractive index, which are in turn caused by fluctuations in temperature and humidity. A standard parameter to characterize the atmospheric turbulence is the refractive index structure parameter, $\mathrm{C}_{\mathrm{n}}{ }^{2}$. More knowledge and understanding about this refractive index structure parameter can help improve the performance of EO systems.

The refractive index structure parameter can be found by measuring it locally or path-averaged, or by using the so-called bulk-theory and deriving it from standard meteorological parameters. One method to measure a path-averaged value of the atmospheric turbulence makes use of a scintillometer ${ }^{1}$. Scintilometers measure the fluctuations of the refractive index structure parameter, which are caused by temperature and humidity differences. Often it is assumed that the humidity contribution to the refractive index structure parameter is small and the refractive index structure parameter $\left(\mathrm{C}_{\mathrm{n}}^{2}\right)$ can be interpreted as the temperature structure parameter $\left(\mathrm{C}_{\mathrm{T}}^{2}\right)$. Usually one is more interested in this temperature structure parameter or the momentum and heat fluxes. When one is using a scintillometer over land, the assumption that temperature is the main contributing factor seems to be reasonable. But it will not hold when a scintillometer is deployed over water, where the fluctuations in humidity certainly contribute to the refractive index structure parameter. Deriving $\mathrm{C}_{\mathrm{T}}{ }^{2}$ from $\mathrm{C}_{\mathrm{n}}{ }^{2}$ becomes more difficult, since one cannot neglect the humidity contribution. But is it possible to use a scintillometer over open water as long as one is only interested in $\mathrm{C}_{\mathrm{n}}{ }^{2}$ ? Only a few examples can be found in the literature where a scintillometer has been deployed over open water ${ }^{2-5}$. In this paper we present some first results of a commercial scintillometer deployed above open water as well as an in-house build transmissometer / scintillometer.

\section{FATMOSE TRIAL - FALSE BAY, SOUTH AFRICA}

The FATMOSE (False Bay ATMOSpheric Experiment) trial is a jointly organized trial by TNO and the Institute of Marine Technology (IMT), taking place in False Bay, South Africa. The trial took place during a whole year, allowing us to capture seasonal variations in the area. Several atmospheric effects, like scintillation, blurring, and refraction effects, were measured during this trial. The measurement path length is in the horizontal direction, $15.7 \mathrm{~km}$ long, and completely over water (see figure 1). It ranges from the IMT in Simon's Town to a beach house in Strandfontein. A second measurement path is about $1.8 \mathrm{~km}$ long and ranges from the IMT in Simon's Town to the Roman Rock Lighthouse (RR). This second measurement path is part of the longer path. A more thorough description of the whole trial can be found in de Jong et.al. ${ }^{6}$.

*m.vaniersel@tno.nl

Atmospheric Optics IV: Turbulence and Propagation, edited by

Alexander M. J. van Eijk, Stephen M. Hammel, Proc. of SPIE Vol. 8161, 81610B

(C) 2011 SPIE · CCC code: 0277-786X/11/\$18 - doi: 10.1117/12.896179

Proc. of SPIE Vol. 8161 81610B-1 
During the FATMOSE trial scintillation was measured using a Scintec BLS900 scintillometer over the $1.8 \mathrm{~km}$ path length. The BLS900 is a large aperture scintillometer that measures the intensity fluctuations at a wavelength of $880 \mathrm{~nm}$ over a maximum path length of $5 \mathrm{~km}$. The receivers were installed on the roof of the IMT at a height of $14.5 \mathrm{~m}$ above mean sea level. The sources were placed on the Roman Rock Lighthouse at a height of approximately $15 \mathrm{~m}$ above mean sea level. An in-house built Multi-Spectral Radiometer Transmissometer ${ }^{7}$ (MSRT) was used to measure the transmission at several wavelengths over a $15.7 \mathrm{~km}$ path length. The receiver was also installed on the roof of the IMT and the sources were installed on the roof of a beach house at Strandfontein. Standard meteorological parameters were recorded by a weather station which was mounted at Roman Rock Lighthouse.

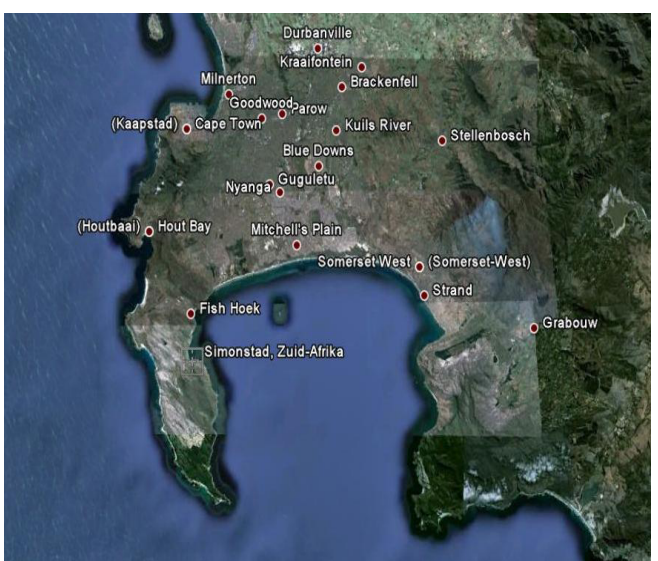

(a)

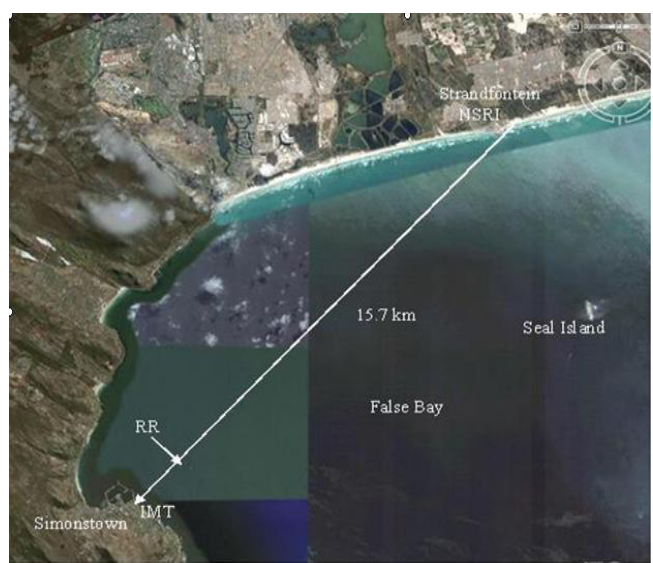

(b)

Figure 1. (a) Overview of False Bay, South Africa. (b) Measurement paths over False Bay. Instruments are placed at the IMT in Simon's Town; sources are placed at Roman Rock (RR) and Strandfontein.

The data presented in this paper come from four months during the trial; December 2009, January, February, and April 2010. Out of these four months 18 days were neglected due to missing data from the BLS900 or the weather station. These four months contain both days with stable as well as unstable conditions. The air temperature ranges from 13.8 to $26.9^{\circ} \mathrm{C}$, the sea temperature from 14.9 to $22.7^{\circ} \mathrm{C}$, and the air-sea temperature difference (ASTD) ranges from -5 to $7^{\circ} \mathrm{C}$. The wind speed ranges from 0 to $22 \mathrm{~m} / \mathrm{s}$ and the refractive index structure parameter $\mathrm{C}_{\mathrm{n}}^{2}$ from $10^{-14}$ to $10^{-18} \mathrm{~m}^{-2 / 3}$. The main wind direction for these four months is around 170 degrees, i.e. south. In figure 2 a histogram of the wind direction is plotted for April 2010. The other months show a similar histogram with a main wind direction around 170 degrees. In figure $2 \mathrm{~b}$ the wind direction is plotted against the wind speed for April 2010. The large(r) wind speeds appear most often around the main wind direction.

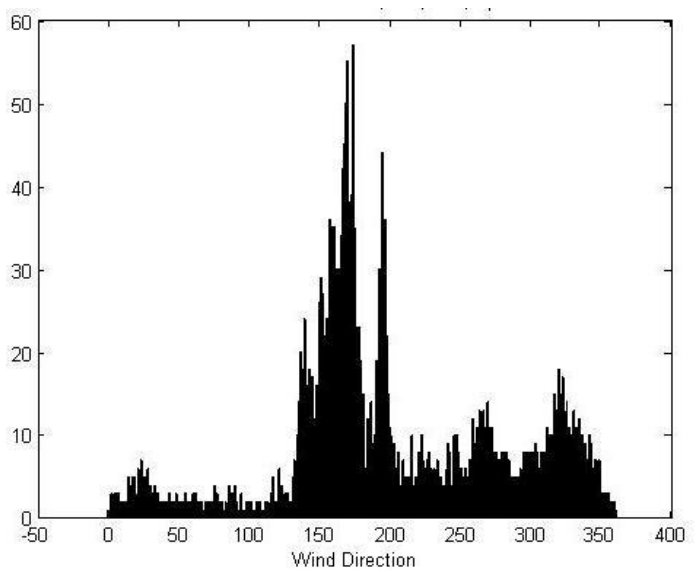

(a)

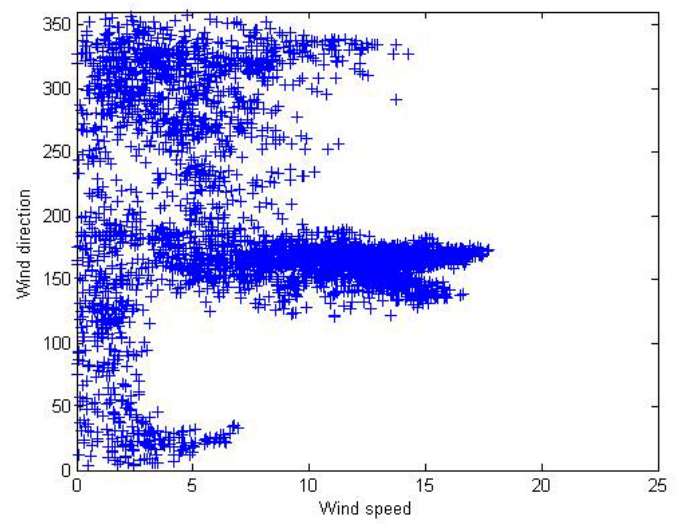

(b)

Figure 2. (a) Histogram of the wind direction for April 2010. (b) Wind direction plotted against wind speed for April 2010. 


\section{SCINTILLATION DATA MEASURED BY THE BLS900 SCINTILLOMETER}

A Scintec BLS900 scintillometer was used to measure the refractive index structure parameter over open water. In first instance we have analyzed the scintillation data of different days and compared the data to the prediction of $\mathrm{C}_{\mathrm{n}}^{2}$ by a micro-meteorological model, TARMOS ${ }^{8}$. Next we have analyzed the scintillation data with respect to certain meteorological parameters.

\subsection{Example days}

For all days the refractive index structure parameter, $\mathrm{C}_{\mathrm{n}}{ }^{2}$, measured by the BLS900 was plotted against time. The corresponding meteorological parameters, recorded by the weather station on Roman Rock Lighthouse, for the days were plotted against time as well. A first check of whether the scintillometer can be used over water was performed by analyzing these plots. The data do not show any unexpected patterns. For two example days, 2 December 2009 and 14 April 2010, the refractive index structure parameter $\left(\log \mathrm{C}_{\mathrm{n}}{ }^{2}\right.$ ) is plotted against time (see figure 3 ). The graph corresponding to 2 December 2009 is an example of a day with stable conditions, while 14 April 2010 is an example of a day with unstable conditions. Examining the meteorological data confirms the stable and unstable conditions for these days. The primary factors of importance were wind speed and air-sea-temperature difference (ASTD).

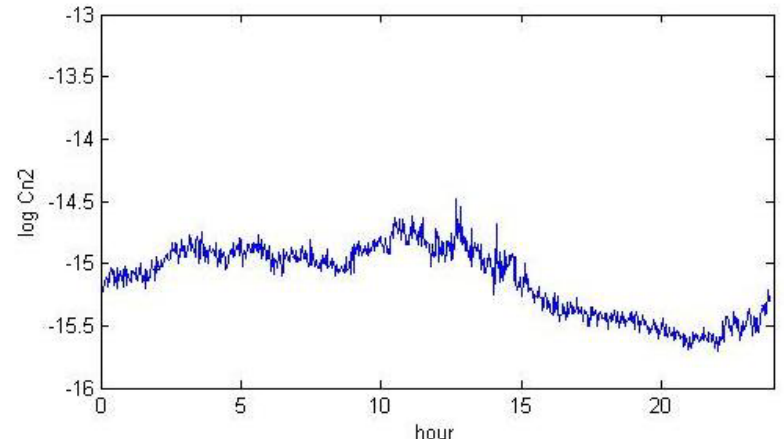

(a)

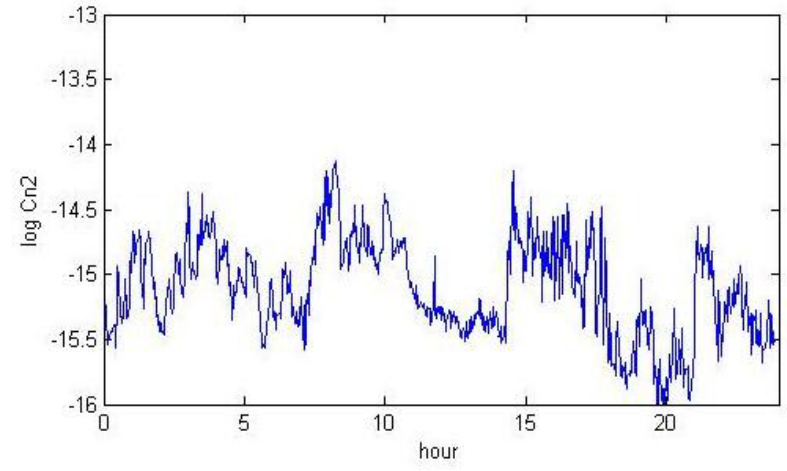

(b)

Figure 3. Refractive index structure parameter $\left(\log \mathrm{C}_{\mathrm{n}}{ }^{2}\right)$ plotted against time for (a) 2 December 2009 and (b) 14 April 2010.

The meteorological data was also used as input to a micro-meteorological model, TARMOS ${ }^{8}$ TARMOS provides a parameterization for the marine atmospheric surface layer on the basis of standard meteorological input parameters using the well-known Monin-Obukhov similarity theory ${ }^{9}$. TARMOS offers two modes: with an assumed relation for $\mathrm{z}_{0 \mathrm{~m}}$, the roughness length for momentum ${ }^{10}$, or with an assumed relation for $\mathrm{C}_{\mathrm{DN}}$, the drag coefficient under neutral conditions ${ }^{11}$. The output of TARMOS consists of the (logarithmic) vertical profiles of wind speed, temperature and water vapor, as well as characteristic turbulence (micrometeorological) quantities.

For each day the value of $\mathrm{C}_{\mathrm{n}}{ }^{2}$, measured by the BLS900, was plotted in 10 minutes averages against $\mathrm{z} / \mathrm{L}$, where $\mathrm{L}$ is the Obukhov length. The measured values were compared to the values predicted by the micro-meteorological model TARMOS. A reasonable to good agreement between measurement and theory was found. For the two example days above these plots are shown in figure 4. 


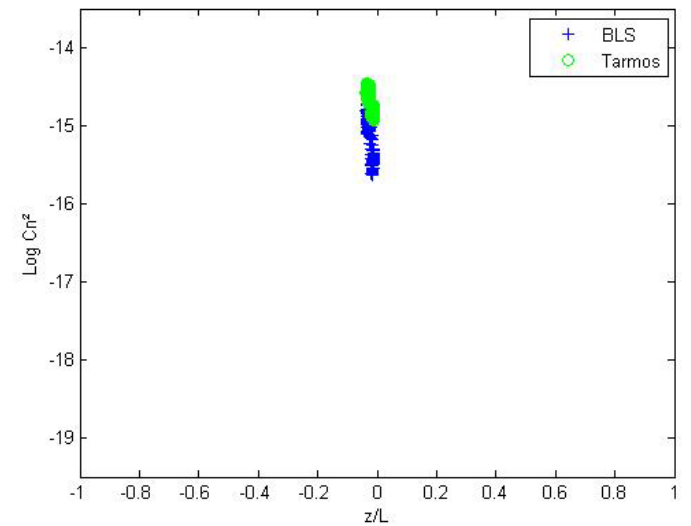

(a)

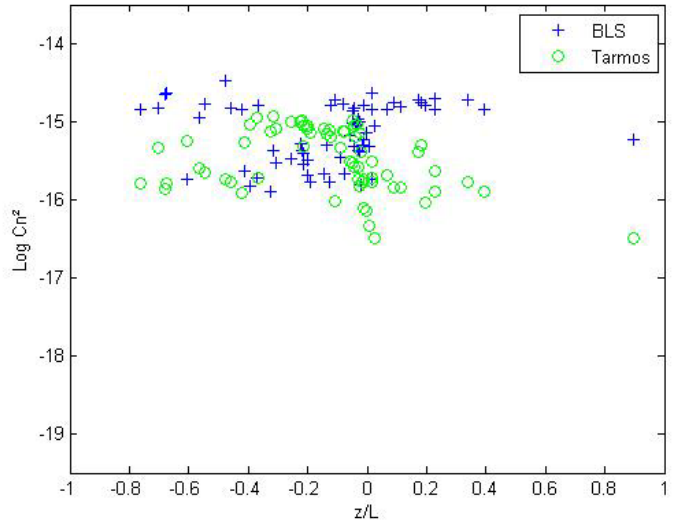

(b)

Figure 4. Refractive index structure parameters $\left(\log \mathrm{C}_{\mathrm{n}}{ }^{2}\right.$ ) as measured by the BLS900 plotted against $\mathrm{z} / \mathrm{L}$ for (a) 2 December 2009 and (b) 14 April 2010. Blue crosses are the measurement values of the BLS900, green circles are the values predicted by the micro-meteorological model TARMOS.

After analyzing the data per day, we also looked at the total data for each month and compared the measured values of the refractive index structure parameter with those predicted by theory. In figure 5 these values are plotted against each other (a) and against $\mathrm{z} / \mathrm{L}$ (b) for January 2010. Again a reasonable agreement with the theory is found, although a small over estimation of $\mathrm{C}_{\mathrm{n}}^{2}$ by the BLS900 is seen for all months.

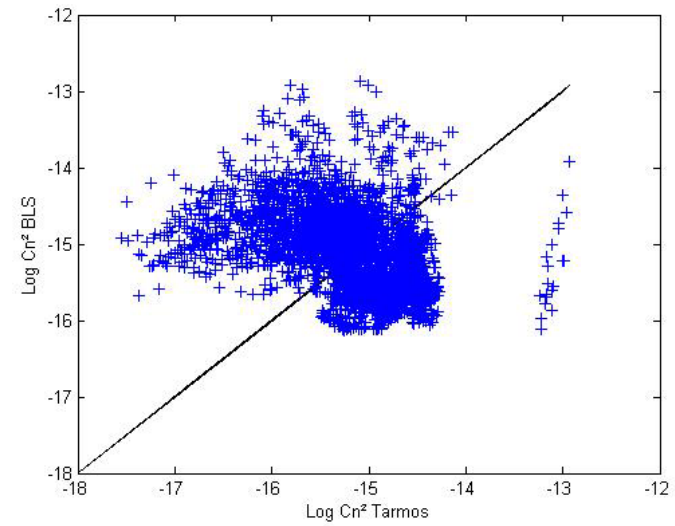

(a)

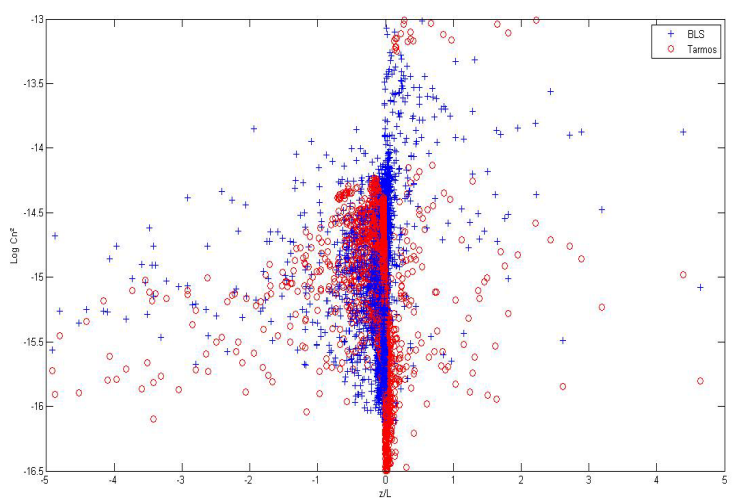

(b)

Figure 5. (a) Refractive index structure parameter as measured by the BLS90 plotted against the refractive index structure parameter predicted by a micro-meteorological model TARMOS for January 2010. (b) Measured (blue) and predicted (red) values of the refractive index structure parameter plotted against $\mathrm{z} / \mathrm{L}$ for January 2010.

\section{$3.2 \mathrm{C}_{\mathrm{n}}^{2}$ dependence on meteorological parameters}

It is known that certain meteorological parameters, like ASTD and wind speed, have an influence on the refractive index structure parameter. In first instance we looked at the influence of the wind speed on $\mathrm{C}_{\mathrm{n}}{ }^{2}$. Figure 6 shows four plots for the month of April 2010 of the refractive index structure parameter against $\mathrm{z} / \mathrm{L}$ for wind speeds higher than $0,5,10$, and $15 \mathrm{~m} / \mathrm{s}$. These plots show that a deviation from the stable conditions (around $\mathrm{z} / \mathrm{L} \sim 0$ ) is found at lower wind speeds. This behavior was observed for all four months. The BLS measurements were also compared with the theory and a good agreement between the measurements and predictions was found for all months. 


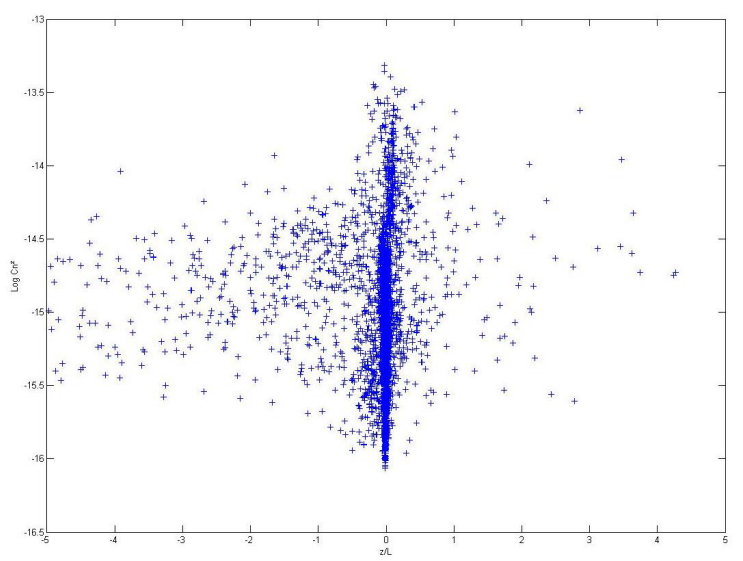

(a)

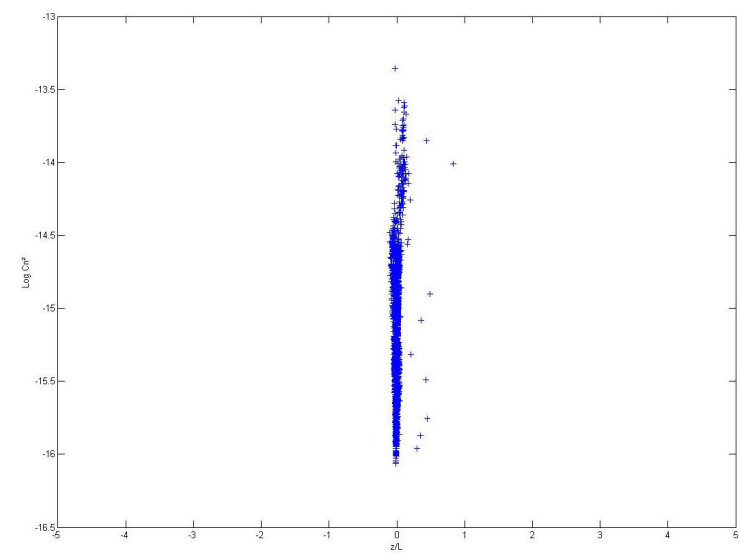

(b)

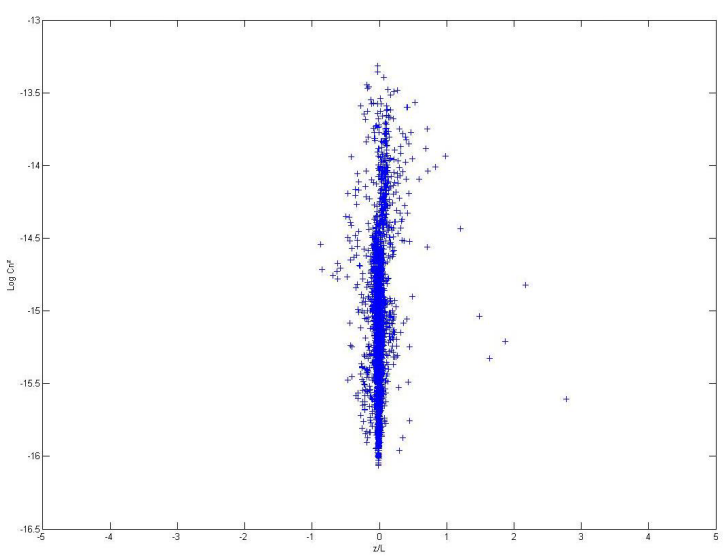

(b)

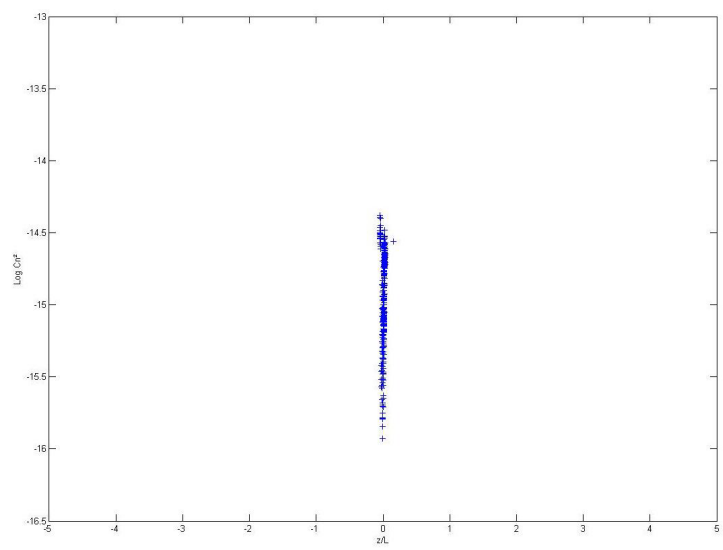

(d)

Figure 6. Refractive index structure parameter against $\mathrm{z} / \mathrm{L}$ plotted for the whole month of April 2010 for (a) wind speeds $u>$ $0 \mathrm{~m} / \mathrm{s}$, (b) wind speeds $\mathrm{u}>5 \mathrm{~m} / \mathrm{s}$, (c) wind speeds $\mathrm{u}>10 \mathrm{~m} / \mathrm{s}$, and (d) wind speeds $u>15 \mathrm{~m} / \mathrm{s}$.

The influence of the air-sea temperature difference (ASTD) on the refractive index structure parameter was also analyzed. In Figure 7 the data for the April 2010 are plotted as the measured refractive index structure parameter against the one predicted by TARMOS for all values of the ASTD, for negative and positive ASTD, and for ASTD $=0$. The measured and predicted values agree quite well in the case of negative ASTD. In the other cases an over estimation by the BLS is seen. Similar results are obtained for the other months.

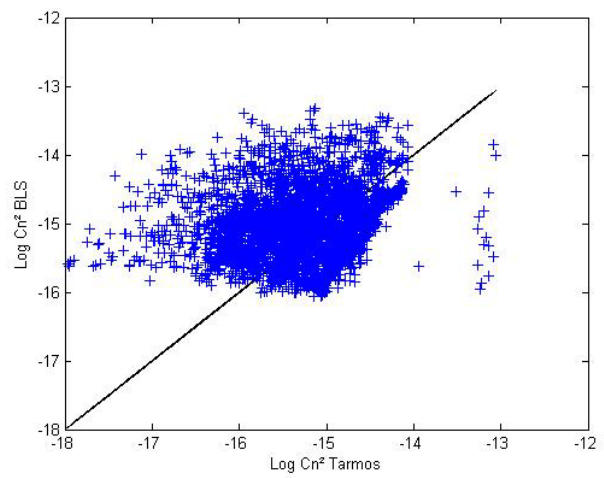

(a)

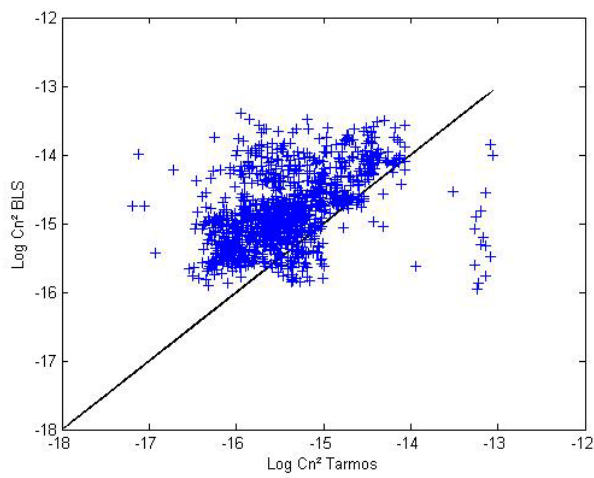

(b) 


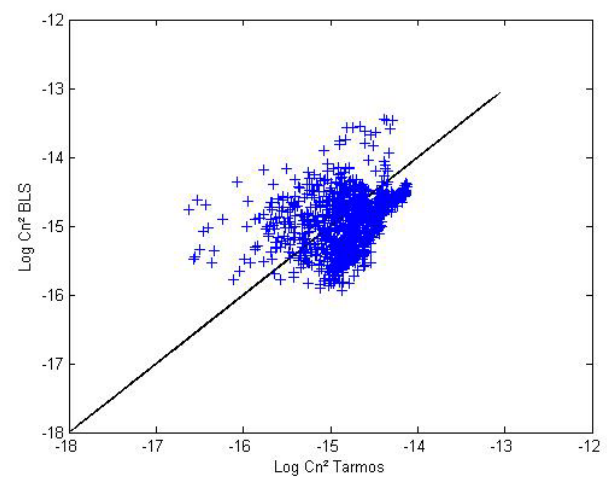

(c)

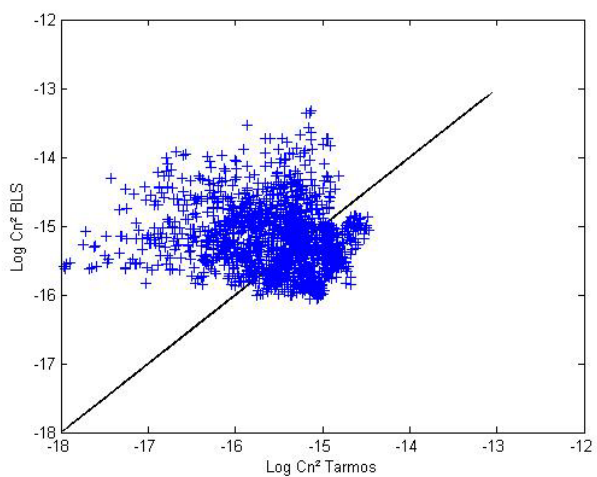

(d)

Figure 7. $\log \mathrm{C}_{\mathrm{n}}{ }^{2}$ as measured by the BLS900 plotted against $\log \mathrm{C}_{\mathrm{n}}{ }^{2}$ predicted by TARMOS (micro-meteorological model) for (a) all values of ASTD, (b) positive ASTD, (c) negative ASTD, and (d) ASTD = 0. April 2010.

\section{THE MULTI-SPECTRAL RADIOMETER TRANSMISSOMETER}

The Multi-Spectral Radiometer Transmissometer ${ }^{7}$ (MSRT) was developed to measure atmospheric transmission in several wavelengths over long distances. It should also be possible to use the MSRT to measure scintillation in several wavelengths. Three (out of maximum seven) channels were used to measure the scintillation at wavelengths of $0.6 \mu \mathrm{m}$, $0.9 \mu \mathrm{m}$, and $1.5 \mu \mathrm{m}$. The path length of $15.7 \mathrm{~km}$ was used to measure the scintillation. Most commercial scintillometers are unable to measure scintillation over such distances, since the signals become saturated ${ }^{12}$. It was first checked when the signal measured by the MSRT is saturated. We used the criterion by Ochs and Hill ${ }^{13}$ and plotted the maximum path length as a function of time. During four months (December 2009, January, February, and April 2010) there were 63 full days of MSRT data. Of these 63 days there was one day on which the signal was not saturated and 16 days on which the signal was completely saturated. For the other 46 days, the signal was, on average, $30 \%$ of the time not saturated. Figure 8 shows one day, 12 April 2010, on which the MSRT signal was completely saturated and one day, 20 December 2009, when the signal is saturated only a part of the time. The red line in the figures denotes the actual path length of $15.7 \mathrm{~km}$.

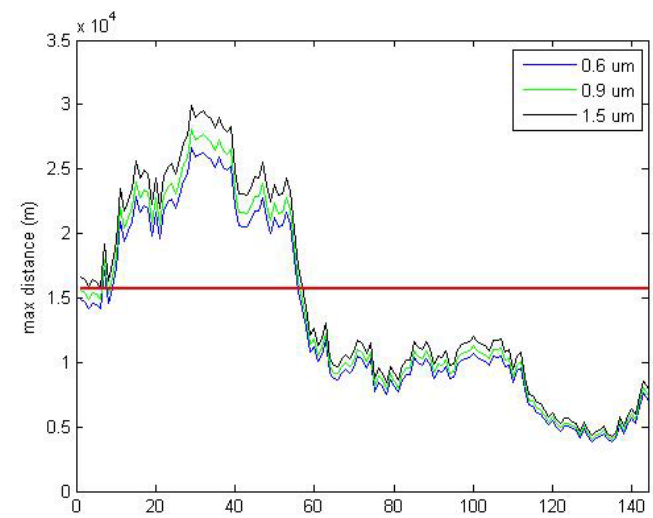

(a)

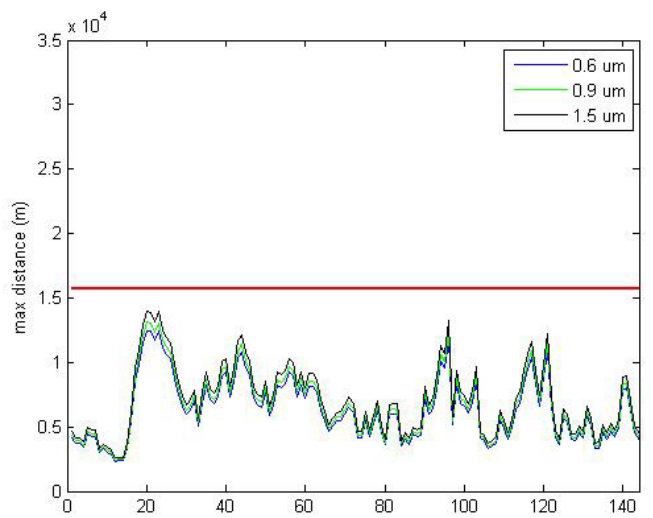

(b)

Figure 8. Maximum path length before the signal becomes saturated for the MSRT channels at 0.6 (blue), 0.9 (green), and 1.5 (black) $\mu \mathrm{m}$. The red line gives the actual path length of $15.7 \mathrm{~km}$. (a) Signal is partly saturated for 20 December 2009. (b) Signal is completely saturated for 12 April 2010.

The refractive index structure parameters derived from the measurements at a wavelength of $0.6 \mu \mathrm{m}$ are plotted against $\mathrm{z} / \mathrm{L}$ together with the measurements of the BLS900 and the prediction from the micro-meteorological model TARMOS. 
In figure 9 the left plot shows all measurement points from the MSRT, the plot on the right-hand side shows only the measurements when the MSRT is not saturated. There is almost no difference between the data of the MSRT with saturation and without saturation. This is observed for all days. A more thorough analysis is needed to understand why there is almost no difference. One question to be asked is whether we should measure different parameters as well if we want to use the MSRT to measure $\mathrm{C}_{\mathrm{n}}^{2}$.

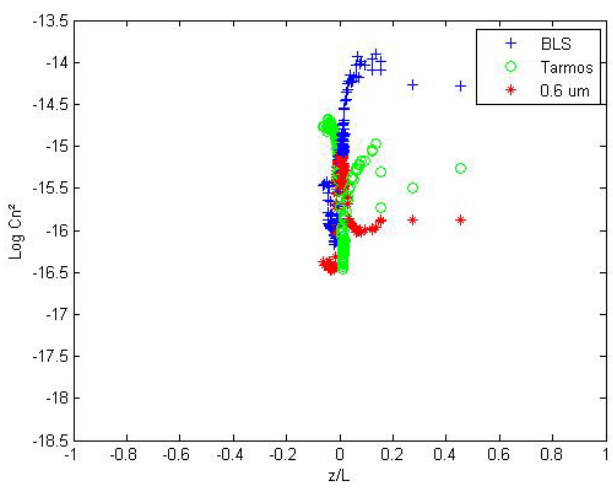

(a)

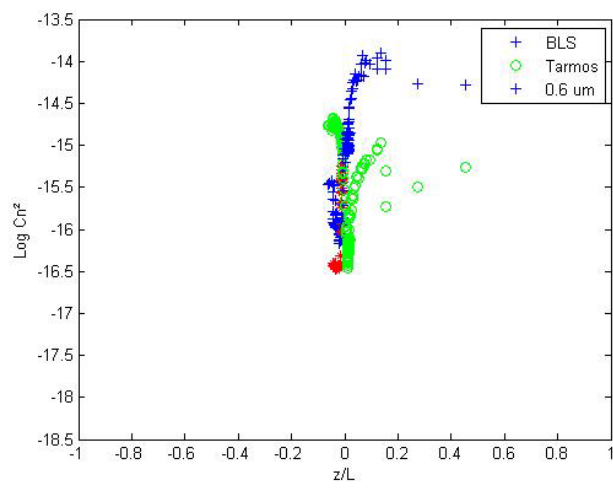

(b)

Figure 9. Refractive index structure parameter measured by the BLS900 (blue), predicted by the TARMOS (green), and measured by the MSRT (red) for 20 December 2010. (a) All measurements from the MSRT. (b) Measurements when the MSRT is not saturated.

\section{CONCLUSIONS}

A commercial scintillometer is used over a measurement path of almost $2 \mathrm{~km}$ over open water. We have analyzed the data and compared them with a micro-meteorological model TARMOS. The results agree reasonably well. Wind speed and air-sea temperature difference (ASTD) seem to be the primary factors of importance. Their influence is shown as well. A deviation from the stable conditions happens at lower wind speeds and / or positive ASTD. The data show that it is possible to use a scintillometer over open water to measure the refractive index structure parameter, $C_{n}{ }^{2}$.

An in-house built multi-wavelength transmissometer / scintillometer was used over a measurement path of almost $16 \mathrm{~km}$. The measurement path is too long for scintillation measurements, since most of the time the signal is saturated. Comparing the MSRT data to the BLS900 data, it is observed that there is almost no difference when the saturated data are ignored. This seems to be the case for all days we analyzed. A more thorough analysis of these data is required.

\section{REFERENCES}

[1] Thiermann, V. and Grassl, H., "The Measurement of Turbulent Surface-Layer Fluxes by use of Bichromatic Scintillation", Boundary-Layer Meteorology 58, 367-389 (1992).

[2] Englisch, G. and Lohse, H., "Comparison of Heat and Momentum Fluxes over Sea derived from LaserScintillation and Eddy-Covariance Measurements", Phys.Chem.Earth 21, No. 5-6, 379-382 (1996).

[3] Frederickson, P.A., Doss-Hammel, S., Tsintikidis, D., and Davidson, K., "Recent results on modeling the refractive-index structure parameter over the ocean surface using bulk methods", Proc. of SPIE Vol.5891, 58910C-1 (2005).

[4] Hammel, S., "Turbulence effects on laser propagation in a marine environment", Proc. of SPIE Vol. 6708, 670804-1 (2007).

[5] Santiago, F., Wilcox, Ch., Chang, M., Font, C.O., Roura, E., and Restaino, S., "Low altitude horizontal scintillation measurements of atmospheric turbulence over the sea : Experimental results", Proc. of SPIE Vol. 6014, 601413-1 (2005).

[6] Jong, A.N. de, Fritz, P.J., Benoist, K.W., van Eijk, A.M.J., and Schwering, P.B.W., "Preliminary results of the FATMOSE atmospheric propagation trials in the False Bay, South Africa, from November 2009 - July 2010", Proc. of SPIE Vol. 7828, 782809-1 (2010). 
[7] Jong, A.N. de, van Eijk, A.M.J., Cohen, L.H., Fritz, P.J., Gunter, W.H., Vrahimis, G., October, F.J., "Application of year-round atmospheric transmission data, collected with the MSRT multiband transmissometer during the FATMOSE trial in the False Bay area", Proc. of SPIE Vol. 8161, 8161-10 (2011).

[8] Kunz, G.J., "A bulk model to predict optical turbulence in the marine surface layer", TNO Physics and Electronics Laboratory, The Hague, The Netherlands, report FEL-96-A053 (1996).

[9] Monin, A.S. and Obukhov, A.M., "Basic laws of turbulent mixing in the atmosphere near the ground", Tr. Inst. Acad. Nauk. Sci., SSR. Inst. Geophiz., 24, 1963-1987 (1954).

[10] Smith, S.D., "Coefficients for sea surface wind stress, heat flux, and wind profiles as a function of wind speed and temperature", J. Geophys. Res, 93, no C12, 15.467-15.472 (1988).

[11] Davidson, K.L., Schacher, G.E., Fairall, C.W., and Goroch, A.K., "Verification of the bulk method for calculating over water optical turbulence", Appl. Opt., 20, 17, pp. 498-502 (1981).

[12] Koshiek, W., Meijninger, W.M.L., de Bruin, H.A.R., and Beyrich, F., "Saturation of the Large Aperture Scintillomter", Boundary-Layer Meteorology 121, 111-126 (2006).

[13] Ochs, G.R. and Hill, R.J., "A Study of Factors Influencing the Calibration of Optical $\mathrm{C}_{\mathrm{n}}{ }^{2}$ meters", NOAA Technical Memorandum ERL WPL-106. 